\title{
EDA and EU Defence Procurement Integration
}

Aris Georgopoulos*

\section{Introduction}

The purchase and development of weapons and related materiel are activities closely linked with some core powers/functions of the Westphalian nation-state, namely national defence. Yet soon after the dawn of the new century major regulatory and policy changes have emerged in this area within the European Union. The process of EU integration in the area of defence procurement reached its (regulatory) culmination with the enactment of the Defence and Security Procurement Directive 2009/81/EU ${ }^{1}$ (hereinafter the DSP Directive).

The present chapter reflects upon the ten years since the establishment of the European Defence Agency (hereinafter EDA) and analyses the role of the latter in the process of European integration in the area of defence procurement. The chapter examines the various initiatives undertaken so far by the EDA in the process of europeanisation of a policy area that has been linked traditionally to core functions of the state and for that reason based upon a decision making process carried out primarily at national level. The chapter argues that the EDA's contribution in the process of European integration in the field of defence procurement has been especially noteworthy. In particular the chapter submits that the EDA played a crucial role in two ways: Firstly it demystified and rendered more acceptable the deliberation at the EU level of issues pertaining to the design, rules and policies of defence procurement/market. Secondly by doing so it provided additional political "legitimisation" to the process of integration of European defence procurement/market integration which led to the enactment of the DSP Directive.

The chapter is organised as follows. Part 2 provides the necessary clarifications regarding the definitions of key concepts. Part 3 places the EDA in its historical and political context and suggests that the EDA should not be seen only as an institutional offspring of political developments in the area of high politics such as the emergence of ESDP but also an institutional product that incorporates lessons learned from previous unsuccessful- efforts of coordination/integration in the area of defence procurement/markets in Europe (but outside the EU). Part 4 examines the EDA initiatives undertaken in the area of defence procurement. Part 5 discusses their impact on the

\footnotetext{
* Assistant Professor of EU and Public Law, Law School, University of Nottingham; Global Governance Fellow at the Robert Schuman Centre of Advanced Studies, European University Institute.

${ }^{1}$ Directive 2009/81/EC of the European Parliament and of the Council of 13 July 2009 on the coordination of procedures for the award of certain works contracts, supply contracts and service contracts by contracting authorities or entities in the fields of defence and security, and amending Directives 2004/17/EC and 2004/18/EC [2009] OJ L216/76.
} 
process of integration in this area. Part 6 synopsises the argument and presents some concluding thoughts.

\section{Preliminary Conceptual and Terminological clarifications}

Before embarking on the examination of the role of the EDA in the process of European defence procurement/market integration it is necessary to clarify some of the terms used and the relevant signified concepts.

To begin with the term defence procurement is used narrowly. In other words it refers to the acquisition of goods and services that have been manufactured, used or intended to be used for purely military purposes (Georgopoulos 2004, 21-28), (SIGMA/OECD, 2011, $2)^{2}$ In other words this definition uses a functional criterion that looks at whether the procurement activity -and the relevant goods or services- are connected with the core of what is generally understood as national defence and national security. Furthermore defence procurement in this sense is often -but not always- characterised by the complexity of the relevant technologies. ${ }^{3}$ According to this definition of defence procurement the size of the relevant market in the EU was approximately $€ 84$ billion in 2012 (EDA 2013, 12)

Furthermore the term/phrase European defence procurement integration ${ }^{4}$ needs to be delimited. European integration is understood in this context as the process of progressive Europeanisation ${ }^{5}$-under the auspices of the EU- of the relevant policy area and the gradual opening up of national defence markets to intra-Union competition. In particular integration is viewed widely and includes looser forms of coordination of national policies without the imposition of a binding EU framework or agenda.

In addition the concept of integration can be further analysed/subdivided into three dimensions: an economic, a legal/regulatory and a political dimension. The present chapter focuses on the examination of the EDA's role particularly on the legal and political dimension of European integration in the field of defence procurement.

\footnotetext{
${ }^{2}$ According to this narrow definition the notion of defence procurement covers for example the acquisition of fighter jets, frigates, munitions, missiles and associated services. This is to be contrasted with a wider definition of defence procurement that covers all acquisitions of goods and services by contracting authorities in the defence sector (including for example the procurement of food supplies, stationary, clothes etc.)

${ }^{3}$ The issue of whether the procurement of "dual-use" technologies are covered by this definition is beyond the remit of this chapter. It suffices to note that the issue has lost some of its practical significance because the field of application of the DSP Directive covers sensitive procurement activities not only related to defence but also to security. Having said that the issue is still relevant with regard to the scope of application of Article 396 TFEU and of the other provisions of the Treaty introducing security related exemptions from the free movement rules (for example Article 36 TFEU).

${ }^{4}$ Alternative versions of the phrase may appear in the text (for example defence procurement/market integration in the EU). They are meant to have the same meaning.

${ }^{5}$ Europeanisation in this context does not mean the replacement of the national by the European. This would be the case if European political integration reached a point where instead of national armed forces there were one European army whose needs would be catered for at EU level. Clearly at the moment this seems a highly uncertain possibility. Instead Europeanisation here involves the inclusion of a European layer in a policy area that customarily has been deliberated, formed and carried out at national level.
} 


\section{Historical and Political Context}

In order to examine the role that the EDA has played in the process of European integration in defence procurement it is important to remind ourselves briefly the historical and political context in which EDA was created and the environment in which it later operated.

Firstly it is worth remembering that the EDA's creation in 2004 was a "last minute" deviation from the original plan. According to this plan the creation of the EDA was part of the changes that were to be introduced by the Treaty Establishing a Constitution for Europe. ${ }^{6}$ Instead the Thessaloniki European Council ${ }^{7}$ decided to dissociate in effect the creation of the EDA from the uncertain, at that time, future of the Treaty Establishing a Constitution for Europe. The European Council tasked the competent bodies of the EU to create within the course of 2004 the EDA; the latter was subsequently established by Council Joint Action 2004/551/CFSP. ${ }^{8}$ Two questions arise in this regard: Firstly, why establish the EDA? Secondly, why the deviation from the original plan?

With regard to the first question the following have been considered as the main reasons for creating the EDA (Georgopoulos, 2005b, 109) namely the need for improving European defence capabilities, the need for streamlining of the institutional framework in European armaments cooperation whilst learning the lessons from previous experiences. Let us now look at each point more closely.

Firstly ever since the Anglo-French St Malo declaration in 1998 the EU has raised expectations ${ }^{9}$ that it would increase its role in the field of defence and security but had failed time and again to match the rhetoric with tangible actions. Particularly in the area of defence capabilities an alarming gap had been demonstrated between US and European armed forces during the intervention in Kosovo. Consequently concerted action in order to improve defence capabilities in the era of reduced defence budgets was seen by the majority of MSs as a necessity.

Secondly although, efforts for coordinating armaments policies in Europe have been already made outside the legal and institutional framework of the $\mathrm{EU}^{10}$ they had up until that point mixed results in terms of achieving their stated aims. Furthermore and perhaps more importantly they had created a complex institutional landscape that was

\footnotetext{
${ }^{6}$ Article I-40 (3).

${ }^{7}$ Thessaloniki European Council June 19 and 202003 Presidency Conclusions, D/03/3, para. 65.

${ }^{8}$ Council Joint Action 2004/551/CFSP of July 12, 2004 on the establishment of the European Defence Agency [2004] O.J. L245/17.
}

${ }^{9}$ For example the establishment of the ESDP and the subsequent creation of a European Rapid Reaction Force.

${ }^{10}$ Initially under the auspices of the Western European Union (hereinafter WEU) in the form of the Western European Armaments Group (hereinafter WEAG) and the Western European Armaments Organisation (hereinafter WEAO) and later on a plurilateral basis amongst some EU MSs under the Joint Armaments Cooperation Organisation (hereinafter OCCAR) and the Letter of Intent Initiative (hereinafter LoI) 
characterised by a degree of duplication (in terms of aims and resources). The creation of the EDA would assist the streamlining of the institutional landscape in the area of armaments and would bring it by and enlarge under the auspices of the EU. ${ }^{11}$

Thirdly all of these initiatives seemed to have missed the elusive balance between inclusiveness on the one hand and flexibility on the other. For example both the WEAG and WEAO were in principle inclusive ${ }^{12}$ (Georgopoulos, 2007a, 208) but as a result they were cumbersome in moving ahead with the process of European cooperation in armaments. On the other hand OCCAR which was created initially by the four largest armaments producing MSs ${ }^{13}$ seemed to introduce more flexibility but at the expense of inclusiveness by bluntly excluding MSs with medium and small sized defence industrial bases (Mawdsley, 2003, 18), (Georgopoulos 2007a, 210). The creation of the EDA incorporated the lessons learned from these initiatives. This is demonstrated in particular by the incorporation of two different categories of ad hoc collaborative projects/programmes namely Category A and Category B. The first draws from lessons from the WEAG and in particular of the EUROPA MoU ${ }^{14}$ and second from OCCAR. (Georgopoulos, 2005b, 111), (Schmitt, 2003a, 94).

After addressing the question "why the EDA" we now turn on the question regarding the deviation from the original plan (i.e. as part of the Treaty Establishing a Constitution for Europe). It has been argued ${ }^{15}$ that two were the main reasons.

Firstly the Iraq war -which started in March 2003- had created an unpleasant rift amongst the governments of EU15 with the immediate consequence of the EU, once again, not being able to frame a united, coherent voice in the area of CFSP. Finding a CFSP related theme or project that would attract the support of the large majority of MSs was deemed a priority. One such theme was identified in the "lower regions" 16 of the "high politics" of CFSP and was none other than the issue of European defence capabilities and armament cooperation.

Secondly it should be remembered that in March 2003 the European Commission had reopened the debate about the role of the EU in the area of defence markets with the

\footnotetext{
11 See the stated aim of the EDA to assimilate and incorporate principles and practices or pre-existing organisations (recital 8 of the preamble of Joint Action 2004/551/CFSP). WEAG's and WEAO's activities were assimilated by the EDA. Consequently WEAG was dissolved in 2005 and WEAO in 2006.

${ }^{12}$ Reflected on their wide membership.

${ }^{13}$ The so-called "big four": France, United Kingdom, Germany and Italy.

${ }^{14}$ The EUROPA MoU was the last attempt to introduce some flexibility in the workings of WEAG/WEAO. It was considered as a response to the establishment of OCCAR.

${ }^{15}$ Georgopoulos (2005b) op.cit.

16 The area of armaments cooperation and defence procurement more generally has been characterised sometimes at gatherings of stakeholders as belonging to "low politics". Although the concepts "high" and "low" politics are not watertight it is argued that it would be more consistent to consider armaments cooperation and procurement as belonging to "high politics" because of their direct link with an area that belongs undisputedly in that category, namely national Defence. However it should be recognised that whilst in the category of high politics because armaments cooperation in addition to political aspects have strong technical/practical and economic ones they can be placed at the lower echelons of "high politics".
} 
publication of COM (2003). ${ }^{17}$ This document demonstrated the Commission's clear aim which was the attempt to introduce supranational elements in the area thus strengthening its role. As it had been suggested at the time it was clear that "more Europe" in the area of defence market was necessary -for the reasons explained above- but what was uncertain was where this process of integration would take place -namely under the Community pillar or under the CFSP or in an inter pillar straddled arrangement- and also what intensity this process of integration would have -particularly with regard to the role and involvement of the Commission, the Court of Justice of the EU (hereinafter CJEU) and the European Parliament (Georgopoulos, 2005a, 560). In other words the decision of the Member States to dissociate the establishment of the EDA from the uncertain and in any case lengthy ratification process of the Treaty should be seen in a context where all the major European institutional stakeholders were trying secure their role in the European defence market integration process and affect the direction of the latter. Thus the speedy establishment of EDA was intended to strengthen the "intergovernmental" pole in the debate that was about to begin about armaments cooperation and regulation in Europe.

\section{European Defence Procurement Integration and EDA}

It is suggested that EDA's role in the process of European defence procurement integration has been important. As it will be shown below under section 5 this is true for both the legal/regulatory and the political dimension of the integration process. In order to demonstrate this observation this part of the chapter will examine some of the initiatives undertaken so far by the EDA that are connected with the area of defence procurement. The exhaustive presentation and analysis of each of the initiatives lie beyond the remit of this chapter. Instead the aim of the analysis is to highlight their combined effect on the process of European defence procurement integration up to now. The relevant initiatives are the Code of Conduct for defence procurement $(\mathrm{CoC})$, the Code of Best Practice in the Supply Chain (CoBPSC), the Code of Conduct on offsets (CoCO), the initiatives for Security of Information (SoI), the initiatives in connection to Security of Supply (SoS) and the Effective Procurement Methods initiative (EPM).

\subsection{Code of Conduct on Defence Procurement}

EDA's first important initiative in the area of defence procurement was the CoC. The latter was launched 1 July 2006 and had as its main aim the introduction of openness, transparency and competition in the European Defence Equipment Market (EDEM).

As with all EDA defence procurement related initiatives the $\mathrm{CoC}$ has the following characteristics: it is voluntary, non-legally binding or enforceable and intergovernmental.

${ }^{17}$ COM (2003) 113 final, European Defence - Industrial and Market Issues: Towards an EU Defence Equipment Policy, Brussels, 2003 
The voluntary character meant that EDA participating MSs were not obliged to join the CoC. Furthermore EDA MSs that decided to join the CoC are free to withdraw from the regime at any given point. For example Spain and Hungary decided not to join immediately -they did so eventually in 2007- (Georgopoulos, 2008, NA8), Romania decided not to join at all and the UK has considered leaving it in the context of the wider reassessment of her participation in the EDA as a whole. ${ }^{18}$ This is linked also with the intergovernmental nature of the $\mathrm{CoC}$. The non-legally binding nature of the $\mathrm{CoC}$ meant of course that the success of the initiative depended entirely on the willingness and political will of the subscribing MSs. It should be remembered that the $\mathrm{CoC}$ is very similar to the "Coherent Policy Document" (CPD), adopted in 1990, which set the principles for the creation of a European Defence Equipment Market (EDEM) under the auspices of WEAG -which had failed precisely because of the MSs' lack of political will (Georgopoulos, 2006a, 51-52, 57-58).

The CoC covers defence procurement contracts that meet the criteria of Article 346 TFEU, ${ }^{19}$ (former Article 296 EC) and whose value exceeds $€ 1$ million. The CoC contains also some exemptions. ${ }^{20}$ One of these is collaborative programmes. Clearly the exclusion of collaborative procurement from the CoC's coverage means that the regime is aimed primarily at off-the-shelf procurement contracts. From this it follows that there is a significant overlap between the CoC's field of application and that of the DSP Directive.

This observation means that the two regimes at least from a legal point of view are antagonistic. Why? Because logically they cannot apply both at the same time Georgopoulos, 2007b, 47). One has to give way to other particularly because the (CoC) is self-regulatory, non-legally binding (CFSP pillar) instrument whereas the DSP Directive is a legally binding and enforceable (first pillar, internal market) instrument. It is important to note that although the $\mathrm{CoC}$ was viewed by some commentators as a potential danger to the acquis communautaire (Trybus, 2006, 690) the Commission formally

\footnotetext{
${ }^{18}$ See Answer of Lord Astor of Hever, Parliamentary Under-Secretary of State, HL Deb, 28 October 2010, c315W.

${ }^{19}$ Article 346 reads:

1. The provisions of the Treaties shall not preclude the application of the following rules:(a) no Member State shall be obliged to supply information the disclosure of which it considers contrary to the essential interests of its security;
}

(b) any Member State may take such measures as it considers necessary for the protection of the essential interests of its security which are connected with the production of or trade in arms, munitions and war material; such measures shall not adversely affect the conditions of competition in the internal market regarding products which are not intended for specifically military purposes.

2. The Council may, acting unanimously on a proposal from the Commission, make changes to the list, which it drew up on 15 April 1958, of the products to which the provisions of paragraph 1(b) apply.

${ }^{20}$ The CoC excluded from its field of application the following types of defence procurerement contracts: i) Research and Development contracts; ii) collaborative procurements; iii) contracts of chemical, bacteriological and radiological goods and services; iv) nuclear weapons; v) nuclear propulsion systems; vi) cryptographic equipment. 
characterised the $\mathrm{CoC}$ as complementary instrument to the DSP Directive ${ }^{21}$ since, according to the Commission, they covered different segments of the defence market. It suffices to note ${ }^{22}$ that the non-complementarity -from a legal point of view- between the two regimes is further evidenced by the fact that the EDA tries to adapt the $\mathrm{CoC}$ to the post DSP directive environment. ${ }^{23}$

It is argued that the most significant practical contribution of the $\mathrm{CoC}$ initiative was the creation of the Electronic Bulletin Board (EBB) portal. This was a central portal where subscribing MSs would announce contract opportunities following a particular format. The centralisation of the publication of these contract opportunities in one portal meant that it would be easier for potential contractors to identify them. ${ }^{24}$ Various kinds of notices were publishable at the EBB (Heuninckx, 2009, 47): a) Prior information notices namely notices that provide in advance general information about future needs of a contracting entity, b) Contract notices inviting the submission of tenders or the submission of requests for participation by interested contractors c) Contract bidder notices containing the list of contractors that have been selected to participate in a particular procurement process, d) Contract notices identifying the successful contractor who has been awarded the contract and e) Request for Information, namely notices through which contracting authorities invite the industry to send information -for example the type of available solutions in the market- about a future procurement contract without necessarily launching a procurement process.

The variety of these notices means that the $\mathrm{CoC}$ apart from a vehicle to improve openness of the national defence markets it has been a useful tool for data collection about these markets and the conduct of the relevant national authorities.

The CoC and the EBB have been used more than other similar previous initiatives and in this sense it should be judged as more successful. However as it will be mentioned further below under section 5 the impact of the $\mathrm{CoC}$ on the defence procurement integration process is not based only on the frequency of its use by the subscribing MSs. I t should be noted that the EBB portal stopped being operational in its original form in June $2013 .^{25}$

\footnotetext{
${ }^{21}$ COM (2005) 626 Communication from the Commission to the Council and the European Parliament on the results of the consultation launched by the Green Paper on Defence Procurement and on the future Commission initiatives, December 2005, Brussels.

${ }^{22}$ For a further analysis as to why these two instruments are antagonistic and not complementary from a legal point of view see Georgopoulos, 2006a, 58-59; Trybus, 2006, 687-690.

${ }^{23}$ Before the entry into force of the DSP Directive the antagonism was theoretical. After the enactment there are specific practical issues that need to be addressed. For this reason the EDA mentions on its website: “... Due to the changes in the European Defence Equipment Market the EDA Steering Board tasked on 12 March 2013 the EDA to analyse the need for a possible new intergovernmental arrangement to replace the Code"

http://www.eda.europa.eu/procurement-gateway/information/eda-codes-arrangements

${ }^{24}$ Instead of having to monitor various national ones as the case was under the WEAG EDEM regime.

${ }^{25}$ Although the EDA website refer to the creation of a new gateway with information on EDA as the reason it is highly likely that this development is also linked with the entry into force of the DSP Directive which requires the publicationof defence procurement contract on the of Official Journal of the EU and as a result Tender Electronic Daily (TED) is the appropriate online platform.
} 


\subsection{Code of Best Practice in the Supply Chain}

The CoBPSC was agreed in 2006 before the entry into force of the CoC. The elaboration of the CoBPSC had been announced in the document that established the CoC. Therefore the two codes were conceptually linked with each other from the very beginning forming integral parts of the EDA's intergovernmental regime on defence procurement. More specifically, as it has been shown, the $\mathrm{CoC}$ aimed at introducing competition at the level of prime contractors whereas the aim of the CoBPSC was to introduce greater transparency and competition in the lower tiers of the defence market, namely at the level of subcontractors and by doing so increase the efficiency, quality, timeliness and consistency in the supply chain.

This means that the CoBPSC is not addressed to contracting authorities (public actors) but to the prime contractors (private actors) that are awarded the defence procurement contract. In other words the instrument aims at affecting the behaviour of enterprises.

It should be remembered at this point that in principle enterprises as market participants are subject to market forces. For this reason according to economic theory these actors in our case prime contractors- would take rational decisions in the selection process of their subcontractors aimed at increasing efficiency, lowering costs, improving quality etc. So what was the need for an instrument that tried to affect the behaviour of enterprises towards a direction that they were prone to follow anyway?

The answer of course is the particularities of defence market(s). As opposed to the conditions of perfect competition upon which economic theory is based the reality in the defence procurement market is different. As we have seen these markets are characterised by fragmentation often upon national protectionist lines and are by definition monosponistic (i.e dominated by one buyer) or at the very least oligopsnonistic (i.e characterised by a small number of buyers). This type of imperfect competition in the market allows for the preferences of the buyer to be fed in the supply chain of the seller. If these preferences -as the case of the European fragmented national defence markets isare informed by protectionist intentions then protectionism will probably contaminate the rest of the supply chain. For this reason it was agreed that the EDA's intergovernmental regime on defence procurement should address this aspect too.

The CoBPSC shares the same characteristics of the CoC; in other words it is an intergovernmental, non-legally binding and non-legally enforceable instrument.

The latter was also implemented through an Electronic Bulletin Board platform (EBB2). It should be notied that the EBB2 could be used by prime contractors to advertise subcontract opportunities not only in relation to defence contracts that meet the conditions of article 346 TFEU -i.e. contracts that are covered by the CoC- but also for defence related subcontracts more generally. It has been argued that the CoBPSC was one of the "carrots" to incentivise compliance (particularly on the part of participating MSs with medium and small defence industrial bases) in the context of a system with virtually no "sticks" (Georgopoulos, 2006b NA147). 
Like the rest of the intergovernmental regime on defence procurement the CoBPSC is under review in the aftermath of the DSP Directive.

Despite the stated objective of the CoBPSC about “....influencing behaviour in the supply chain to encourage fair competition at the national level and across the [subscribing MSs] "26 the latter did not deal with the issue of offsets and related practices even though it is through these types of practices that protectionist (or to use a more neutral term domestic industrial) preferences are fed from the demand side (public sector) to the prime contractor level (private sector) and then diffused into their supply chain arguably distorting competition. In fact the term offsets is not mentioned in the CoBPSC at all. Instead offsets were the subject of another EDA code of conduct discussed immediately below.

\subsection{The Code of Conduct on Offsets}

As already mentioned one of the areas of the European defence procurement market that all the regulatory initiatives at EU level had refrained from addressing directly up until the relevant EDA initiatives was the treatment of offset practices (known also as offsets or industrial compensations). The first time ${ }^{27}$ that an EU regulatory initiative included offsets as its main focus was the EDA CoCO.

Before examining the $\mathrm{CoCO}$ it is important to explain what offset practices are.

Offsets are practices followed in the context of defence procurement whereby procuring States try to safeguard a return of their "investment" -i.e. the payment given to a foreign defence contractor for the acquisition of defence equipment or related services- for their domestic industry (Georgopoulos, 2011, 30). Offset policies can be implemented in a variety of ways and offsets may manifest themselves in various forms. Although there is not a standardized nomenclature or categorization of offset practices as such, it is argued that offsets can be categorised as follows ${ }^{28}$ (Georgopoulos, 2011, 33):

\footnotetext{
${ }^{26}$ The Code of Best Practice in the Supply Chain, para. 5 http://www.eda.europa.eu/docs/documents/CoBPSC final

${ }^{27}$ Previously the European Commission had simply stated its general disagreement with offset practices (see for example COM (2006) 779 final, Interpretative Communication on the Application of Article 296 of the Treaty in the field of Defence Procurement, Brussels. For an analysis of the Communication see Georgopoulos, $2007 \mathrm{~b}$. 45). Before the establishment of the CoCO the EDA had commissioned a relevant study, Final Report Study on the effects of offsets on the Development of a European Defence Industry and Market, 2007. The study is available online at:

http://www.eda.europa.eu/docs/documents/EDA 06-DIM-

022_Study_on_the_effects_of_offsets_on_the_Development_of_a_European_Defence_Industry_and_Market_1
}

\footnotetext{
${ }^{28}$ See Georgopoulos, 2004, 344 and also Final Report Study on the effects of offsets on the Development of a European Defence Industry and Market, 2007, 3.
} 
- Direct offsets: Offset transactions that are directly related to the defence items or services imported by a participating Member State. For example under this category offset practices can take the form co-production, subcontracting, training, licensed production, technology transfer. The distinguishing factor and principal point of reference for these offset practices is the subject of the main defence procurement contract (namely they take place in the context of the delivery of the defence contract that forms the subject of the main transaction between the procuring government and the foreign contractor).

- Indirect offsets: Offset transactions that are not directly related to the defence items or services imported by a procuring government. In turn Indirect offsets are subdivided into:

○ Defence related indirect offsets. The latter are not linked with the delivery of the contract that forms the subject matter of the main transaction between the procuring government and the foreign contractor but still are to be implemented in the field of defence. For example the main contract regards the acquisition of 40 new aircraft by state $\mathrm{A}$ but the offset contract regards the purchase by the defence contractor of the main contract (the winner of the competition) of defence related services (for example maintenance services) from companies established in State A. However these services are not related with the purchase of the 40 new aircraft by State A. Instead they can be used by the defence contractor in other future contracts with this or other countries.

○ Non-defence related indirect offsets (also known as "civil" offsets). This kind of indirect offsets are not linked with the subject matter of the main defence procurement contract and they are implemented outside of the field of defence. For example the main contract regards the acquisition of 40 new aircraft by state A but the offset contract concerns the purchase by the foreign defence contractor of fax machines produced from companies established in State A. In this case the indirect offset contract has nothing to do with the field of defence.

As already implied the aforementioned categorisation is meant to function as schematic representation of what in reality is a more complex typological environment. It may be difficult in practice to place some offset contracts (only or strictly) under one of these categories. This is because modern defence systems contain technologies that are used in both the defence and civil sectors. These technological crossovers mean essentially that the distinction between defence and civil technologies is less clear-cut than it used to be. As a result although the distinction between direct and indirect offsets seems in principle to be a little bit more straightforward, ${ }^{29}$ for an increasing number of indirect offset contracts the classification under the defence indirect and non-defence indirect offset categories may be a challenging moot point.

\footnotetext{
${ }^{29}$ Even though due to the hybrid character of modern technology, logically direct offsets may also include technologies that are not purely defence in nature (for example dual use technologies).
} 
The discussion -let alone treatment- of offset practices generates mixed views and strong emotions. On the one hand offsets are seen as practices that distort competition in the market. ${ }^{30}$ On the other hand they are viewed as an important tool for the development of domestic defence industrial and technological capabilities, particularly for developing countries. In the context of the EU offsets also raise questions about their compatibility with EU Law. The legal treatment of offsets in the EU has always been controversial. This is why the contribution of the EDA in discussing offsets more openly and -as we will see further below- providing a preliminary roadmap for their treatment within the EU must be considered as significant.

It is worth mentioning that before the elaboration of the CoCO the EDA had commissioned an independent study that examined the impact of offset practices on the development of a European defence market. Although the study did not provide conclusive answers regarding the overall impact of offset practices on the development of the European defence industry and market it made clear on the one hand that as a matter of principle these practices are not a priori compatible with EU law but from a practical point of view -if used properly- they may prove useful tools for industrial development. Furthermore the study acknowledged that offsets are not only a European phenomenon and that they are frequently used around the world.

The CoCO came into force on 1 July 2009. ${ }^{31}$ The stated aim of the CoCO was the improvement of the competitive conditions in the European Defence Equipment Market (EDEM) and also the promotion of a competitive European Defence Technological and Industrial Base (EDITB). ${ }^{32}$

Although a detailed analysis of the CoCO is beyond the scope of the present chapter ${ }^{33}$ it suffices to note the following points.

Firstly the CoCO put forward a proposition for dealing with offsets that was based on a constructive and pragmatic approach. This approach recognised that although offsets can create market distortions in the context of perfect competition conditions they can also work as mechanisms that assist the creation a level playing field in a market characterised by imperfect competition conditions; particularly if the relevant market is influenced by political

\footnotetext{
${ }^{30}$ They also raise concerns regarding their lack of transparency and for this reason are seen as a factor that can assist the breeding of corruption in the field of defence. The lack of (or limited) transparency of course is not only a characteristic of offset arrangements but it has characterised defence procurement more generally. A detailed discussion of corruption in the defence sector lies beyond the remit of this chapter. For an analysis of corruption in the context of offsets see Transparency International's report Defence Offsets: Addressing the risks of Corruption and Raising Transparency, 2010, available online at: http://archive.transparency.org/publications/publications/other/defence offsets

${ }^{31}$ See A Code of Conduct on Offsets Agreed by the EU Member States Participating in the European defence Agency (version approved on May 3 2011) available on line at:

http://www.eda.europa.eu/docs/default-source/documents/The_Code_of_Conduct_on_Offsets.pdf

${ }^{32}$ In accordance with the Strategy that was agreed by the EU Defence Ministers. See "Strategy for European Defence Technological and Industrial Base”, Brussels, May 14, 2007, 5, available online at:

http://www.eda.europa.eu/docs/documents/strategy_for_the_european_defence_technological_and_industrial_b ase.pdf

${ }^{33}$ For a detailed analysis of the CoCO see Georgopoulos, 2011.
} 
considerations like the defence procurement market. ${ }^{34}$ By recognising this reality explicitly the $\mathrm{CoCO}$ adopted a more useful stance -as opposed to the doctrinal stance of principle against offsets often articulated by the Commission- - that furthered the debate regarding the treatment of offsets. In other words the EDA through the CoCO, instead of the demonization of offsets considered the possibility of using of this mechanism in a way that supports the EDITB - principle of instrumentality- while attempting to minimise its adverse effects on the development of a fair and competitive EDEM -principle of restraint Georgopoulos, 2011, 35). The EDA in-house study on abatements ${ }^{35}$ was a tangible demonstration of this constructive and pragmatic approach.

Secondly by adopting the aforementioned stance the EDA manage to convince participating MSs to materialize in practice the two main principles enshrined in the CoCO namely transparency and mutual trust. The EDA via the CoCO managed to shed light on a sensitive area often characterised by secrecy. It managed in particular to convince participating MSs to reveal/share information about their national offset policies. In this way MSs became both providers and recipients of the relevant information.

The EDA managed to create -to a degree at least- an environment of mutual trust for information sharing and as a result participating MSs did reveal in the relevant portal -for the time that the portal was still operational- substantial information ${ }^{36}$ regarding their national offset policies. It is worth mentioning that like other EDA online portals the offset portal was accessible not only to participating MSs but also to the general public.

Like the other pre DSP Directive initiatives of the EDA, the CoCO has been under review in the aftermath of the enactment and transposition in the national legal orders of the new directive. ${ }^{37}$ MSs are considering whether to continue or alter their offset policies. ${ }^{38}$

\subsection{Security of Information}

Another aspect of defence procurement where the EDA has played a constructive role is SoI. The latter is important in the context of defence procurement and can function as a trade

\footnotetext{
${ }^{34} \mathrm{CoCO}, 2$

${ }^{35}$ Abatements: A Pragmatic Tool to Facilitate the Development of European Defence Equipment Market, EDA, 2010, Brussels, available online at:

https://www.eda.europa.eu/docs/documents/Abstract_-_Study_on_Abatements For a presentation and analysis of the study on abatements see Georgopoulos, 2011, 37-39.

${ }^{36}$ For more on the specific type of information that MSs agreed to share on the portal see Georgopoulos, 2011, 37.

${ }^{37}$ Although the DSP Directive does not deal with offset practices directly the Commission, has issued a Guidance Note of offsets where it explicate its strict stance vis-à-vis offsets. Although the Guidance note is not legally binding it nevertheless affects de fact the decision of MSs whether and how to implement offset policies. The Guidance note is available online at: http://ec.europa.eu/internal_market/publicprocurement/docs/defence/guide-offsets_en.pdf

${ }^{38}$ Perhaps this process of reviewing explains the fact he EDA portal where information about national offset policies is no longer accessible. It was accessible at least until 6 January 2014, see Heuninckx, 2014, 47.
} 
barrier if standards and processes followed by the various MSs differ significantly. ${ }^{39}$ This is also linked with the observation made earlier regarding the overarching aim of EDA's initiatives in the field of defence namely the building of trust amongst the participating MSs. Already from 2006 the EDA contributed to the process for improving the environment regarding SoI by agreeing on common minimum standards for ensuring industrial security. ${ }^{40}$

Furthermore the EDA established recently an electronic portal ${ }^{41}$ where the various national legislations, policies that are linked with SoI can be found. ${ }^{42}$ This is particularly important in the post DSP Directive regulatory environment. It should be remembered that dealing with SoI is one of the priority areas of the new regime.

The EDA has been mandated by MSs to identify ways to remove SoI barriers in defence procurement amongst MSs. Through the exchange of information on national SoI standards and policies the SoI portal constitutes the first step in this process.

\subsection{Security of Supply}

Another practical yet crucial aspect of the defence procurement market where the EDA has being playing a notable role is SoS. The latter covers cases such as the long term support of military equipment during their life cycle, the ability to supply forces deployed abroad and to deal with unplanned increases of operational requirement due to unforeseeable events (Heuninckx, 2014, 34). Often SoS considerations have been used for justifying national offset policies and other protectionist measures.

It should be noted that although the DSP Directive includes provisions on $\operatorname{SoS}^{43}$ that deal with some legal issues for example whether SoS considerations may be taken into account as award criteria it does not provide for a specific plan for dealing with the practical issues

\footnotetext{
${ }^{39}$ For example as mentioned in the SoI portal (see below fn 41) if there is no bilateral or multilateral agreement or arrangement between Member States, the relevant national contracting authorities can refuse to recognize the security clearance from non-domestic firms. In the context of the internal market this could be considered as a market access barrier that underlines the creation of a competitive EDEM.

${ }^{40}$ See EDA Steering Board Decision No. 2006/18 on "Security of Information between Subscribing Member States (sMS)," which set certain "Common Minimum Standards on Industrial Security" available online at: http://www.eda.europa.eu/docs/documents/common-minimum-standards-on-industrial-security-.pdf
}

\footnotetext{
${ }^{41}$ The EDA SoI portal was launched on 1 July 2014 and is available online at: http://eda.europa.eu/soiportal/default.aspx

${ }^{42}$ The portal contains the following information for every participating MS: the applicable legal basis; the objectives of the national SoI policy; the minimum duration of the initial granting of Personnel Security Clearances (PSC) and Facility Security Clearances (FSC) and the duration for which they are valid; the existing bilateral/multilateral SoI agreements; the national policies and practices on sharing classified information; the recognition of the PSCs and FSCs; the contractual terms on SoI defence related contracts; relevant national authorities; relevant national SoI documents; the National SoI Point of Contact.

${ }^{43}$ Artricle 23 DSP Directive.
} 
linked with SoS. $^{44}$ In order to understand some of these let us consider the following examples:

- MS A and MS B have a surge in the demand for a specific type of munition at the same time. The relevant needs of both MSs are catered for by an economic operator established in MS A. This economic operator cannot satisfy both (unscheduled) demands simultaneously. Clearly MS A can take measures -for reasons of public interest, national security etc- to oblige the economic operator established in her jurisdiction to prioritise the needs of MS A (explicitly or implicitly over those of MS B).

- MS A who disagrees with specific foreign policy decisions and actions of MS B decides to block or procrastinate the delivery of munitions by economic operator A established in her jurisdiction to MS B.

The aforementioned examples try to highlight some of the practical challenges with regard to SoS. The EDA initiatives in the context of SoS try to fill precisely this gap between the legal treatment of SoS in the defence procurement process and the practical issues that arise in this area.

In particular the EDA elaborated in 2006 a Framework Agreement for SoS which focused in cases of operational urgency ${ }^{45}$ initially. Following the enactment of the DSP Directive the scope of the Framework Agreement was expanded ${ }^{46}$ in order to cover also cases of defence acquisitions in peacetime where there is no operational urgency. This enhanced Framework Agreement is supported by the Code of Conduct on Prioritisation $(\mathrm{CoCP})^{47}$ which is an instrument that aims to involve the industry in the SoS framework, by establishing a way for the industry to demonstrate its commitment to meet Member States SoS requirements in defence procurement. ${ }^{48}$

These instruments are supported by an online portal ${ }^{49}$ which aims to enhance transparency and provide useful information about national legislations, policies linked with SoS. ${ }^{50}$ Like with the initiatives on offsets and SoI, the SoS initiative aims to enhance mutual trust amongst Member States.

\footnotetext{
${ }^{44}$ This is also the case for the Commission's Guidance Note on SoS. The latter is available online at: http://www.eda.europa.eu/docs/documents/guide-sos_en.pdf

${ }^{45}$ EDA Steering Board decision 2006/17 on a Framework Agreement for Security of Supply between Subscribing Member States(sMS) in Circumstances of Operational Urgency available online at: http://www.eda.europa.eu/docs/documents/2006-17-eda-sb.pdf For a more detailed discussion of the Framework Agreement see Heuninckx, (2008, 13-15).

${ }^{46}$ See enhanced framework Agreement on SoS available online at http://www.eda.europa.eu/docs/defaultsource/projects/framework-arrangement-for-security-of-supply.pdf

${ }^{47}$ The CoCP was established on 15 May 2014 and is available online at: http://www.eda.europa.eu/docs/defaultsource/documents/code-of-conduct-on-prioritisation.pdf?Status=Temp

${ }^{48} \mathrm{CoCP}, 1$.

49 The SoS portal was launched in 2011 and is available online athttp://eda.europa.eu/SOSWeb/

${ }^{50}$ For example the relevant national legal bases for SoS; SoS objectives; relevant national bodies and areas of responsibilities; the role of SoS requirements in procurement processes; contractual terms used on SoS; existing bi- and multilateral agreements on SoS.
} 


\subsection{Effective Procurement Methods}

The last EDA defence procurement related initiative that we consider in this chapter is the EPM. $^{51}$

The EPM is the implementation of a specific task set for the EDA by the Treaty of the EU, namely the promotion of harmonisation of MSs' operational requirements and the adoption of compatible effective procurement methods. ${ }^{52}$ The EPM is linked with and is intended to complement the wider Pooling and Sharing initiative ${ }^{53}$ of the EDA.

In particular the EPM initiative aims to identify ways, methods and areas where MSs (or some of them) may consolidate their demand in the context of off-the-shelf procurement thus achieving economies of scale, reducing duplication and improving interoperability. Areas with such potential for demand consolidation are amongst others transport or logistic support, training, standard vehicles, ammunition, legacy weapon systems and communication equipment. $^{54}$

After the identification of areas for demand consolidation the EPM initiative could use any of the main options for joint procurement for example acquisition through a lead nation that procures on behalf of other MSs, the option for procuring through an international body or organisation such as NAMSA or OCCAR and the option for the EDA to act as a central purchasing body on behalf of MSs. This possibility is envisaged by the DSP Directive ${ }^{55}$ and is also supported by the EDA's legal framework. ${ }^{56}$

The third option means that the EDA could become an one-stop-shop where the identification, shaping of common demand and actual procurement could take place. So far two pilot EPM case studies have been implemented. ${ }^{57}$

\section{Contemplating EDA's Impact on Defence Procurement Integration}

After the discussion of the various EDA initiatives in the field of defence procurement this part of the chapter tries to elucidate their impact on the legal/regulatory and political

\footnotetext{
${ }^{51}$ The EPM initiative was launched on 7 July 2011.

52 Article 45 (1) (b) TEU.

${ }^{53}$ The Pooling and Sharing (P\&S) is focuses primarily on MS led projects to increase collaboration in military capabilities. Because the P\&S scope is wide we cover in this chapter only aspects of the initiative that are relevant in the area of defence procurement. See Code of Conduct on Pooling and Sharing available on line at: http://www.eda.europa.eu/docs/news/code-of-conduct.pdf

${ }^{54}$ EDA EPM Fact Sheet, June, 2012 available online at: https://www.eda.europa.eu/docs/documents/factsheetepm.pdf

${ }^{56}$ Particularly after Council Decision 2011/411/CFSP (OJ L 183/16 ) which reinforced EDA's legal framework by taking into account the changes introduced by the entry into force of the Lisbon Treaty.

${ }^{57}$ The first is the Counter-IED Training European Guardian (beneficiaries Luxembourg and Austria); the second is the Basic Logistics Services for the EU Battle Group (beneficiaries Austria, Czech Republic and Germany).
} 
dimensions of European defence procurement integration process. Although these two dimensions are interconnected an attempt to envisage theimpact of EDA's initiatives on either of them separately is considered useful in order to better appreciate EDA's overall contribution in the integration process.

\subsection{Impact on Legal/Regulatory Dimension of Defence Procurement Integration}

From the point of view of the legal/regulatory aspect of integration a quick glance at the state of play of European regulation in defence procurement may lead to the precipitate conclusion that the impact of EDA's initiatives has been limited. This is because the model of regulation that these initiatives put forward, namely what could be termed as coordinated intergovernmental self-regulation did not prevail in the end. Instead it was the Community method model proposed by the Commission initiatives that provided the main framework (DSP Directive) and the forum of regulation (first pillar, internal market) in this area.

However we argue that this impression would be utterly misguided. To explain this we distinguish three main ways in which the initiatives of the EDA contributed crucially to the legal/ regulatory integration in defence procurement.

Firstly the EDA initiatives provided important information about the state of play of defence procurement markets in the EU. This information was later used by the Commission to strengthen the case for the adoption of a tailor made instrument of the first pillar in order to facilitate the functioning of the internal market in defence procurement.

In particular the contribution of the $\mathrm{CoC}$ cannot be underestimated. The information available on the EBB portal showed clearly that despite their earlier pronouncements MS left significant part of their defence procurement contract opportunities outside the CoC's more transparent and more competitive framework. Not only that but also many of the contract opportunities published on the EBB portal concerned goods and services that were not in the list of 1958, ${ }^{58}$ which, according to Article 346 (2) TFEU constitutes the point of reference with regard to the material scope for the application of Article 346 (1) (b) TFEU. ${ }^{59}$ Instead these contracts -for example military boots- should have been procured according to the public sector procurement directive. ${ }^{60}$ In other words in some cases MS not only were they not opening their defence procurement markets but in fact they were circumventing their obligations under the public sector procurement directive. This demonstrated vividly the level of misunderstanding amongst some MS of the limits of Article 346 TFEU exemption.

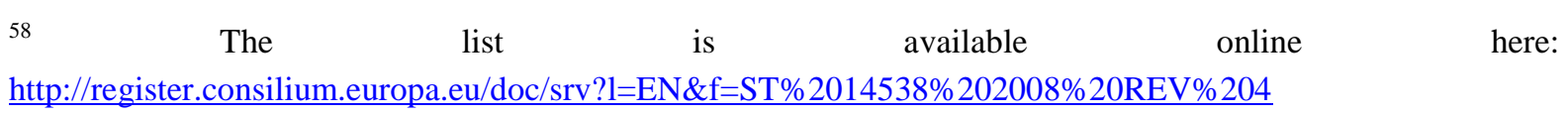

\footnotetext{
${ }^{59}$ As explained earlier under section 4.1 a prerequisite for the application of the $\mathrm{CoC}$ is the fulfilment of the conditions of Article 346 TFEU.

${ }^{60}$ Directive 2004/18/EC of the European Parliament and of the Council of 31 March 2004 on the coordination of procedures for the award of public works contracts, public supply contracts and public service contracts [2004] OJ L134/114
} 
Furthermore even in the case of contracts that fulfilled the conditions of Article 346 TFEU the use of the $\mathrm{CoC}$ revealed a paradox that in effect strengthened the argument of the Commission for the adoption of a tailor made directive in the internal market. The paradox is the following: If MSs are willing to share publically through the EBB portal information about sensitive defence procurement opportunities then why not do this through the OJ following the usual rules for public sector procurement? MSs could only justify their not using the EU procurement rules by arguing that the public sector directive obliged contracting authorities to use by default the open or restricted procedures. ${ }^{61}$ These procedures leave very little margin for discretion to contracting authorities. It is precisely this point that the Commission addressed in its proposal for the DSP Directive in order to alleviate the concerns -and eliminate excuses- of MSs by introducing the negotiated procedure with prior publication, which allows for both flexibility and discretion, as a standard procedure. ${ }^{62}$

These observations show that without the EDA initiatives the collection of information and evidence -sometimes "incriminating" evidence- by the Commission relevant for building the case for a DSP Directive, would have been more difficult.

Secondly the EDA initiatives had a clear impact on the content and direction of the DSP Directive and the other Commission initiatives. For example the material scope of DSP directive has been clearly influenced by the MSs preferences included in the EDA initiatives. In particular the exemption of collaborative procurement based on research and development ${ }^{63}$ echoes the same exemption found in the CoC. Furthermore the provisions on subcontracting $^{64}$ are heavily influenced by the CoBPSC and the CoCO. Likewise the renewed emphasis on SoI and SoS found in the instruments/initiatives of the Commission can be traced back to the relevant EDA initiatives.

Thirdly the EDA initiatives provide a complementary pathway that assists MSs to implement specific aspects the DSP Directive framework. For instance as presented above, ${ }^{65}$ this is the case for the SoS and SoS initiatives of the EDA which have been adapted to assist MSs with the application of the relevant parts of the DSP Directive.

\subsection{Impact on Political Dimension of Defence Procurement Integrations}

From the perspective of the political dimension of defence procurement integration this chapter argues that the impact of EDA's initiatives has been fundamental.

Firstly EDA's creation alone with its mandate signalled a move towards more Europe, or better more EU, in the area of defence procurement.

More importantly it is argued that the EDA had a "numbing" effect on the reactionary and atavistic reflexes of Member States in the context of defence procurement integration through

\footnotetext{
${ }^{61}$ The more flexible negotiated procedure with or without prior notice or the competitive dialogue can be used only if specific conditions are met.

${ }^{62}$ Article 25 DSP Directive.

${ }^{63}$ Article 13 (C) DSP Directive.

${ }^{64}$ Article 21 DSP Directive.

${ }^{65}$ See above sections $4.4,4.5$ and 4.6
} 
the deliberation of its soft law instruments and policy initiatives. It should be remembered that the EDA is a particular kind of EU Agency. It comes under the CFSP pillar, is financed by participating MSs, not the EU Budget, and its staff is composed of seconded national officials. The Commission takes part in the deliberations of the Steering Board but without any voting rights. This environment seems to have created a more fertile ground for the discussion of national preferences and contemplation about the design of policy instruments in the area. In this sense the use of the various online portals for sharing information amongst MSs showed on the one hand to Member States that using a more open transparent (European) approach in the context of defence procurement activities was not an anathema and perhaps could lead to useful outcomes. Likewise, as discussed above ${ }^{66}$ these exercises provided the Commission with useful information for "selling" the proposal of the DSP Directive to the MSs.

Furthermore the EDA managed to create a forum where constructive discussion of the different preferences between MSs with significant domestic defence industrial capacity and those with small and medium sized ones could take place without hampering flexibility. It should be remembered that such differences had led to the creation of OCCAR initially as an "exclusive" club. The setup of the EDA created an environment where all participating Member States had -or were led to believe that they had- equal stakes in the process. We argue that this environment appears to have played a significant role in preparing a more receptive atmosphere for what was to follow, namely the Commission regulatory "defence package".

These observations could be supported by a number of facts. For example although Spain and Hungary decided not to join the $\mathrm{CoC}$ initially they did so a year after. Even more interestingly Denmark who participates neither in the EDA nor in the non-legally binding $\mathrm{CoC}$ because of its general opt out of CFSP initiatives that may have defence and military implications voted in the Council of Ministers in favour of the enactment of the legally binding and enforceable DSP Directive.

In other words the EDA through its initiatives played a legitimising role of a process of discussion of policies/preferences linked with core state functions (the "tools of national sovereignty" (de Vestel 1998, 197)) at the EU level. This legitimising role in effect assisted the successful conclusion of the Commission's initiatives. Although it is difficult to prove the counterfactual we argue that without the existence of the EDA the adoption of the Commission's defence package might not have been certain (or at the very least it would not have been adopted in the record time in which it was). After all we have the example of the unsuccessful attempt for a process of moderate harmonisation of defence procurement that the Commission had undertaken in the late 90 s. $^{67}$

\footnotetext{
${ }^{66}$ Section 5.1.

${ }^{67}$ Although it could be argued that the timing of the EU Commission's first initiatives in the second half of the 90s was not the most auspicious due to the economic and political outlook at the time we argue that it could still function as a useful point of comparison for the following reasons: a) Although the economic and political context in the late $90 \mathrm{~s}$ was not identical with the economic and political situation in 2003 -we use 2003 as a point of reference because it coincides with the invitation of the EU Parliament to the Commission to take
} 
Moreover the observant student of defence procurement integration will notice that behind the triumphant words of press releases about the "harmonisation" of defence procurement in the EU in reality the DSP Directive leaves many issues "flexibly unclear" -and many questions unanswered. The DSP Directive includes many exemptions and has other aspects that require further clarification. This could be described as a process of "controlled communitarisation" of defence procurement. In other words the new regulatory framework is characterised by "incomplete contracts" that will need to be renegotiated as the integration process progresses. ${ }^{68}$ The role of the EDA remains crucial in this regard.

\section{In Lieu of Conclusions - A look into the future}

The present chapter examined EDA's role in European defence procurement integration thus far and argued that its impact has been significant. It analysed in particular the contribution of EDA's initiatives in the legal/regulatory and political dimension of this process.

The prima facie antagonism between the initiatives of the regulatory and policy initiatives of the EDA and the Commission has had one clear outcome: the furtherance of regulatory and political aspects of integration in defence procurement. To use a metaphor, the initiatives of the EDA and the Commission could be described as a game of chess where each player responds to the moves of the other and tries to establish an advantage; however what is important from the point of view of the integration process is not so much the specific moves but the fact that the game is being played. In this regard the presence of the EDA was key for the game to start and more importantly to continue.

So what does the future hold for EDA in the field of defence procurement? We identify four strands where the EDA can continue to play a central role in the post DSP Directive landscape. We also identify a necessary condition for this to happen.

Firstly the exemption of collaborative R\&D procurement from the field of application of the DSP Directive may provide an incentive to MSs to engage in collaborative projects -since among other advantages it would guarantee some work sharing for their domestic industry something that based on the standard rules of the Directive is not possible in principle. In such a case the EDA could play a role in facilitating the coordination of the operational requirements of participating MSs.

Secondly as already mentioned under section 4.6 the EDA could in time become a central purchasing body in the area of off-the-self procurement for participating MSs; initially for

action- they were not so fundamentally different in a way that it would prevent a meaningful comparison b) the points where the previous initiative failed we would argue could be linked with the lack of a dedicated body/agency below the level of the Council of Ministers where the preferences of the Member States could be presented and debated in a continuous way by medium ranked national defence officials/experts.

${ }^{68}$ Without attempting a detailed analysis here one could identify the following areas: the operational limits of the "subcontracting" provisions of the DSP Directive; SoI; SoS; the issue of offsets which has not been touched by the directive directly -the guidance note of the Commission is not part of the "contract" but rather the clarification of the position of one influential player in the next step of renegotiation; collaborative procurement; government to government procurement. 
simple standardised products and progressively for more sophisticated equipment -depending on the level of coordination of MSs operational requirements.

Thirdly the EDA could work in unison with the Commission in order to provide more clarity to some important yet challenging policy areas linked with the implementation of the DSP Directive such as the SoI and SoS.

Fourthly and linked with the above the EDA could play the role of honest broker in the next phases of integration in defence procurement between MSs and the Commission. For example an area where the EDA ought to act constructively is the area of offsets. The area remains a point of contention between the Commission and some MSs. Another important area is that of standardisation in the field of defence and security procurement.

Finally it is important to note that all this is based on a necessary condition: the continuing willingness of MSs to engage in further integration in defence procurement. It was submitted above in section 5.1 that the greater transparency brought by the EDA initiatives led unwittingly perhaps- to the strengthening of the Commission's position. Will the realisation of this fact lead MSs to return to their old more secretive and cautious ways? This is not impossible. If this were to happen then the EDA would become a victim of its own success. A lot will depend eventually on the way that the Commission will enforce the DSP Directive. Perhaps this explains the cautious approach followed by the Commission thus far; it seems that the stakeholders seem to realise that the priority is the continuance of the chess game and not the pronouncement of a precipitous - and thus pyrrhic- victory over the "opponent".

\section{Bibliography}

de Vestel, Pierre (1998) "The Future of Armaments Cooperation in NATO and the WEU" in Eliassen. K. Ed. Foreign and Security Policy in the European Union, (Sage), London

Georgopoulos, Aris (2004) European Defence Procurement Integration: Proposal for Action within the European Union, PhD Thesis, Nottingham University.

Georgopoulos, Aris (2005a) “Defence Procurement and EU Law” E.L.Rev. 30: 559-572

Georgopoulos, Aris (2005b) "The New European Defence Agency: Major Development or Fig Leaf?" PPLR, 14: 103-112

Georgopoulos, Aris (2006a) “The European Defence Agency's Code of Conduct for Armaments Acquisitions: A Case of Paramnesia?” PPLR, 15: 51-61

Georgopoulos, Aris (2006b) "European Defence Agency: The New Code of Best Practice in the Supply Chain", PPLR, 15, NA143

Georgopoulos, Aris (2007a) "The European Armaments Policy: A conditio sine qua non for the European Security and Defence Policy?" in European Security Law (White, Nigel and Trybus, Martin eds) Oxford, OUP: 199-222 
Georgopoulos, Aris (2007b) "The Commission's Interpretative Communication on the Application of Article 296 EC in the Field of Defence Procurement" PPLR, 16, NA 43

Georgopoulos, Aris (2008) "Comment on the Recent Developments in European Defence Procurement Integration Initiatives” PPLR, 17: NA 8

Georgopoulos, Aris (2011) "Revisiting Offset Practices in European Defence Procurement: The European Defence Agency's Code of Conduct on Offsets” PPLR, 20, 29-42

Heuninckx, Baudouin (2008) "Towards a Coherent European Defence Procurement Regime: European Defence Agency and European Commission initiatives”, PPLR, 17, 1-20

Heuninckx, Baudouin (2009) “The European Agency Electronic Bulletin Board: a survey after two years" PPLR, 18, 43-66

Heuninckx, Baudouin (2014) Security of Supply and Offsets in Defence Procurement: What's New in the EU? PPLR, 23, 33-49

SIGMA (2011) Defence Procurement, Public Procurement Brief 23, September 2011, available at: http://www.sigmaweb.org/publications/Defence_Public_Procurement_2011.pdf EDA (2013) Defence Data 2012, available at: http://www.eda.europa.eu/docs/defaultsource/eda-publications/defence-data-booklet-2012-web

Thessaloniki European Council June 19 and 202003 Presidency Conclusions, D/03/3, available at: http://europa.eu/rapid/press-release_DOC-03-3_en.htm

Mawdsley, Jocelyn (2003) “The European Union and Defence Industrial Policy”, Bonn, 2003, Bonn International Center for Conversion (BICC), Paper 31

Schmitt, Burkard (2003a). "European Armaments Cooperation: Core Documents", Paris, Institute for Security Studies, European Union, Chaillot Papers No. 59

Trybus, Martin (2006) "The New European Defence Agency: A Contribution to a Common European Security and Defence Policy and a Challenge to the Community Acquis?" C.M.L. Rev. : 667-703 